\title{
anatomy
}

Original Article

\section{Morphologic and morphometric analysis of mandibular lingula}

\author{
Öznur Özalp ${ }^{1}$ (D), Hande Salım² (D), Busehan Bilgin ${ }^{1}$ (D), Serra Öztürk² (D), Merve Sarıaya Doğan² (D), \\ Mehmet Berke Göztepe ${ }^{3}$ (D), Engin Çalgüner ${ }^{4}$ (D), Muzaffer Sindel ${ }^{2}$ (D), Alper Sindel ${ }^{1}$ (iD \\ ${ }^{1}$ Department of Oral and Maxillofacial Surgery, School of Dentistry, Akdeniz University, Antalya, Turkey \\ ${ }^{2}$ Department of Anatomy, School of Medicine, Akdeniz University, Antalya, Turkey \\ ${ }^{3}$ School of Medicine, Akdeniz University, Antalya, Turkey \\ ${ }^{4}$ Department of Anatomy, School of Medicine, University of Kyrenia, Kyrenia, Turkish Republic of Northern Cyprus
}

\begin{abstract}
Objectives: The aim of this study was to determine the morphology and location of mandibular lingula in relation to the surrounding structures in adult mandibles to provide data that can be used during oral and maxillofacial procedures.

Methods: This study was performed on 50 dry adult mandibles of Turkish population. The shape of the lingula was examined bilaterally and classified into four types. Osteometric measurements were performed on both sides using a digital caliper. Statistical analysis was performed to determine the differences between right and left side measurements.

Results: The most frequently encountered shape of lingula was triangular type (42\%). The assimilated type was not observed among the mandibles studied. The mean distance between the lingula and the anterior border of the ramus of the mandible and between the lingula and the posterior border of the ramus of the mandible was measured as $16.86 \pm 2.73 \mathrm{~mm}$ and $14.7 \pm 1.6$ $\mathrm{mm}$, respectively. The mean height of the lingula was measured as $11.92 \pm 2.03 \mathrm{~mm}$. No statistically significant differences were observed between the right and left side measurements for any parameters.
\end{abstract}

Conclusion: The findings of present study may be used for various oral and maxillofacial surgical procedures and help surgeons in avoiding inferior alveolar nerve injury during mandibular osteotomies.

Keywords: inferior alveolar nerve; injury; lingula of the mandible; mandibular foramen; sagittal split ramus osteotomy

Anatomy 2020;14(1):16-21 @2020 Turkish Society of Anatomy and Clinical Anatomy (TSACA)

\section{Introduction}

Mandibular lingula (lingula of the mandible) is a remarkable, sharp bony projection located on the medial aspect of the ramus of the mandible to which the sphenomandibular ligament is attached. ${ }^{[1]}$ The lingula forms the orifice of mandibular foramen (MF), also known as inferior alveolar foramen. MF transmits the inferior alveolar neurovascular bundle to the mandibular canal. The inferior alveolar nerve (IAN) provides the sensory innervation of pulps of all mandibular teeth, the lower lip and skin over the chin.

IAN is prone to injury during various surgical interventions of the mandible such as sagittal split ramus osteotomy, post-traumatic reconstruction, tumor resection. These complications may cause psychological and social impairment leading a significant decrease in patients' quality of life. ${ }^{[2]}$ In this regard, the lingula serves as a reliable anatomical landmark for identifying the location of MF to prevent complications related with IAN damage when performing above-mentioned surgeries (Figure 1). Furthermore, precise determination of MF is obligatory for surgical treatment of IAN-related neuralgia and inferior alveolar nerve block anesthesia which is essential for most dental procedures in mandible. ${ }^{[3]}$ 
Considering the fact that metric characteristics of mandible vary among ethnic groups, several studies have been performed to better understand the morphology and anthropometric location of lingula on different population. ${ }^{[4-6]}$ Although two studies have attempted to investigate the morphology of lingula using cone beam computed tomography (CBCT) data, there is scant information regarding Turkish population. ${ }^{[7,8]}$

The aim of this research was to determine the morphology and location of mandibular lingula in relation to surrounding structures in dry adult mandibles of Turkish population for to provide data that can be used during oral and maxillofacial procedures.

\section{Materials and Methods}

This study has been performed on 50 dry adult mandibles belonging to Anatolian people of unknown sex and age obtained from the bone collection of Department of Anatomy, Faculty of Medicine, Akdeniz University to determine the different shapes and positions of the lingula. This study was conducted with the permission taken from the local ethics committee of the University (Approval number: 70904504/287).

The shape of the lingula was examined bilaterally and classified into four types including triangular, truncated, nodular and assimilated lingula, as previously reported by Tuli et al. ${ }^{[6]}$ (Figure 2).

Osteometric measurements were performed on both sides using a digital caliper with following parameters (Figure 3):

- Horizontal distance between the anterior border of ramus of mandible and the anterior rim of mandibular foramen (A),

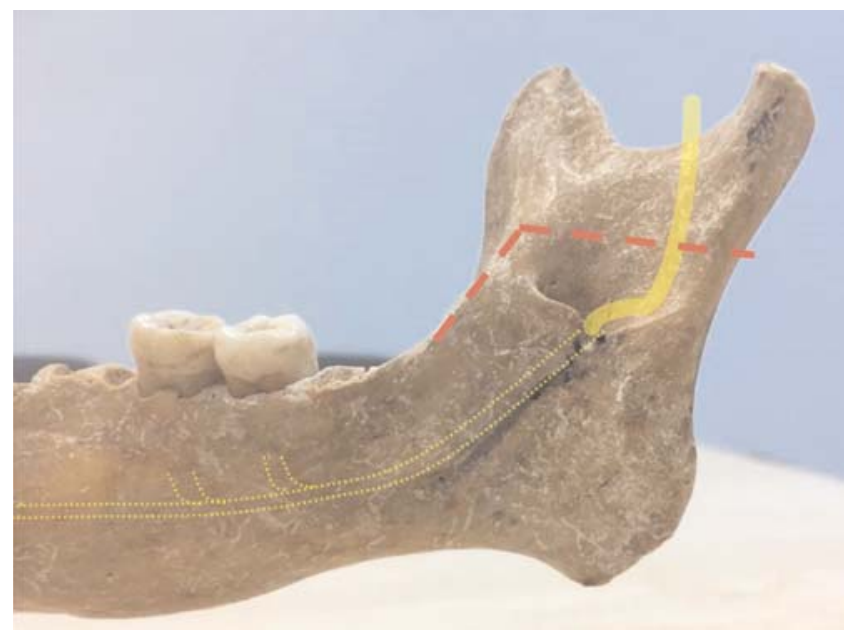

Figure 1. Schematic illustration of the formation of mandibular foramen by lingula and transmission of the inferior alveolar neurovascular bundle (yellow line). Red lines represent the borders of bone cut in sagittal split ramus osteotomy.

- Horizontal distance between the posterior rim of mandibular foramen and the posterior border of ramus of mandible (P),

- Vertical distance between the alveolar socket of second mandibular molar tooth and the superior rim of mandibular foramen $(\mathrm{H})$.

The horizontal distances were measured parallel to the occlusal plane of the molars, whereas the vertical distances were measured perpendicular to the occlusal plane of the molars.

\section{Statistical Analysis}

The classification of the lingula shapes was described in numbers and percentages. The data regarding all distances
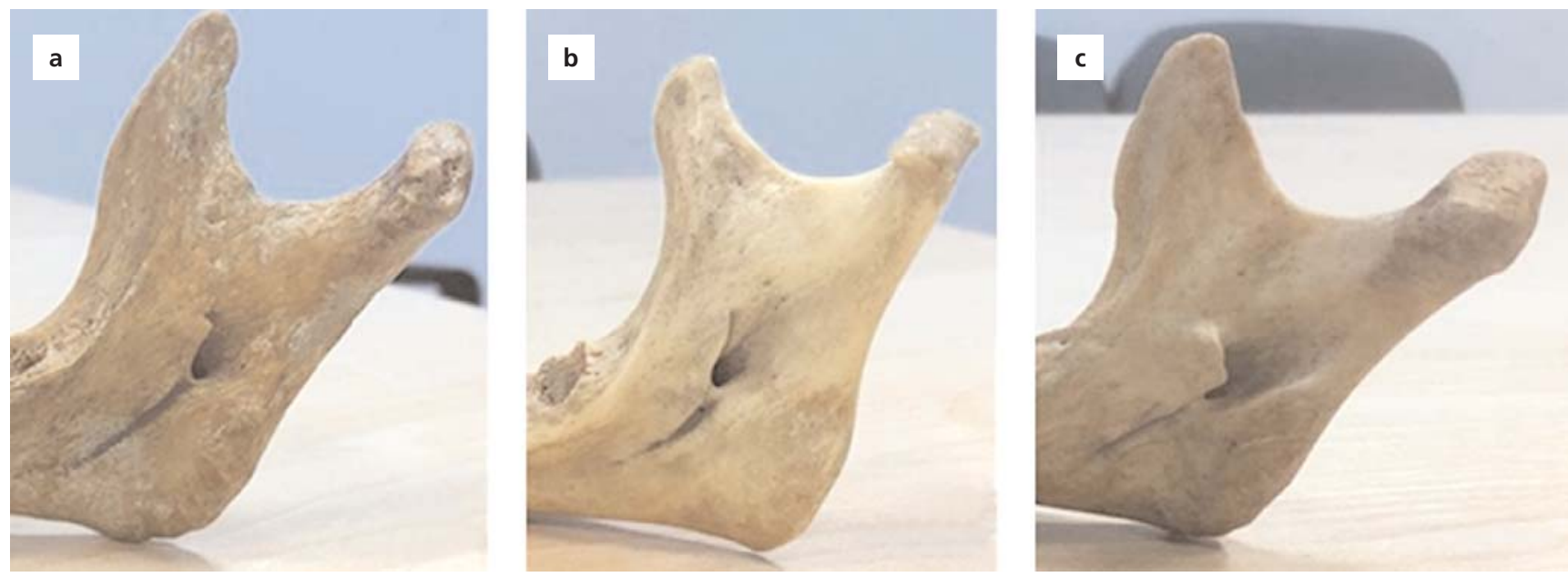

Figure 2. Different types of lingula; (a) triangular, (b) nodular, (c) truncated. 
studied was organized with descriptive statistics such as means, standard deviation (SD) and percentage distributions. The normality of the data was assessed using the Shapiro-Wilk test. The mean values of the right and left sides were compared using t-test (differences were considered significant at $\mathrm{p}<0.05$ ) with the statistics software IBM SPSS Statistics for Windows (Version 22.0,IBM Corp. Armonk, NY, USA, released 2013).

\section{Results}

The most frequently encountered shape of lingula was triangular type. The triangular lingula was present totally in 42 sides ( $42 \%$ ) and in 14 mandibles (28 sides) it was present bilaterally. The unilateral assessment showed that 9 of triangular lingula occurred on the right side and 5 on the left. The truncated type was found totally in 28 sides (28\%) and in 9 mandibles (18 sides) it was present bilaterally. Four of the unilateral truncated lingula were on the right side and 6 on left. The nodular lingula were noticed totally on 30 sides (30\%). In 10 mandibles (20 sides) it was bilaterally present. Four of the unilateral nodular lingula were on the right side and 6 the on left. The assimilated type was not observed among the mandibles studied (Table 1).

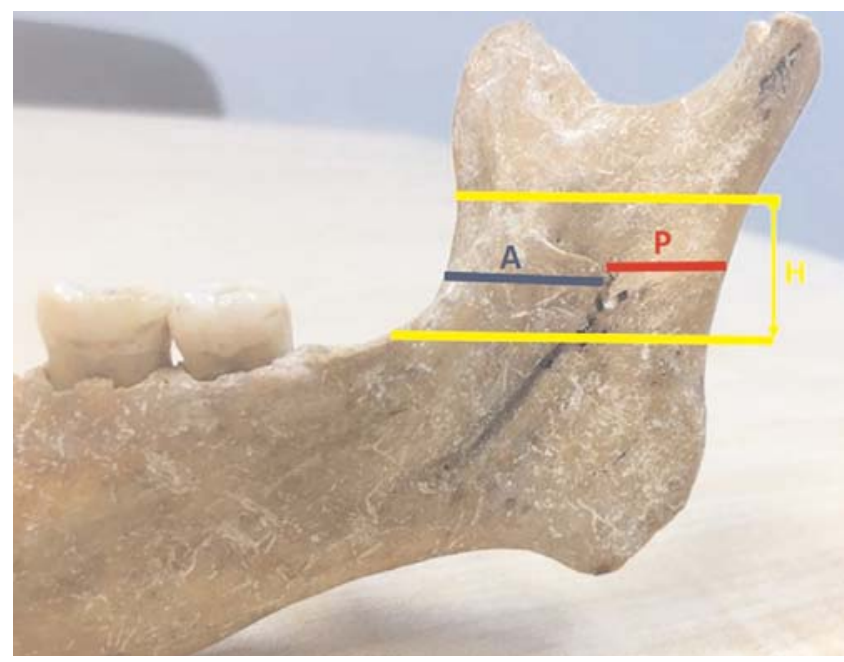

Figure 3. Outline of the points and distances measured on the mandibles.

The height and distance of lingula from anterior and posterior borders of ramus of mandible is shown in Table 2. The mean distance between the lingula and the anterior border of ramus of mandible (A) was $16.86 \pm 2.73 \mathrm{~mm}$, and it was $16.72 \pm 2.57 \mathrm{~mm}$ on the right side and $16.99 \pm 2.9 \mathrm{~mm}$ on the left side. No statistically significant difference was

Table 1

Distribution lingula by shapes and sides.

\begin{tabular}{lcccc} 
Shape of lingula & Bilateral & Right side & Left side & Total \\
\hline Triangular & $14(42.42 \%)$ & $5(14.7 \%)$ & $9(26.47 \%)$ & $42(42 \%)$ \\
Truncated & $9(27.27 \%)$ & $6(17.64 \%)$ & $4(11.76 \%)$ & $28(28 \%)$ \\
Nodular & $10(30.3 \%)$ & $6(17.64 \%)$ & $4(11.76 \%)$ & $30(30 \%)$ \\
Assimilated & 0 & 0 & 0 & 0 \\
\hline
\end{tabular}

Table 2

Descriptive data regarding the measurements of the height $(\mathrm{H})$ and distances between anterior $(\mathrm{A})$ and posterior $(\mathrm{P})$ borders of ramus of mandible to lingua.

\begin{tabular}{lccccc} 
& $\mathbf{n}$ & Min. $(\mathbf{m m})$ & Max. $(\mathbf{m m})$ & Mean \pm SD $(\mathbf{m m})$ & Shapiro-Wilk test \\
\hline A-right side & 50 & 11.54 & 23.8 & $16.72 \pm 2.57$ & $16.99 \pm 2.9$ \\
A-left side & 50 & 11.25 & 25.58 & $16.86 \pm 2.73$ & .573 \\
A-total & 100 & 11.25 & 25.58 & $14.85 \pm 1.53$ & .705 \\
P-right side & 50 & 11.35 & 17.74 & $14.55 \pm 1.67$ & .248 \\
P-left side & 50 & 11.35 & 17.3 & $14.7 \pm 1.6$ & .167 \\
P-total & 100 & 11.35 & 17.74 & $11.75 \pm 1.86$ & .073 \\
H-right side & 50 & 9.89 & 13.61 & $11.99 \pm 1.96$ & .098 \\
H-left side & 50 & 10.03 & 13.95 & $11.92 \pm 2.03$ & .31 \\
H-total & 100 & 9.89 & 13.95 & .122 \\
\hline
\end{tabular}


found between the right and left side measurements regarding A values ( $\mathrm{p}=0.623$ ) (Table 3). The mean distance between the lingula and the posterior border of ramus of mandible $(\mathrm{P})$ was $14.7 \pm 1.6 \mathrm{~mm}$, and it was $14.85 \pm 1.53 \mathrm{~mm}$ on the right side and $14.55 \pm 1.67 \mathrm{~mm}$ on the left side. Similarly, B values did not show significant difference between the right and left sides $(\mathrm{p}=0.387)$ (Table 3).

The mean height of the lingula $(\mathrm{H})$ was $11.92 \pm 2.03$ $\mathrm{mm}$ and it was $11.75 \pm 1.86 \mathrm{~mm}$ on the right side and $11.99 \pm 1.96 \mathrm{~mm}$ on the left side $(\mathrm{p}=0.542)$.

\section{Discussion}

Lingula is a critical clinical landmark for identification of mandibular foramen from which inferior alveolar neurovascular bundle enters to mandibular canal. It serves as a main reference point for determining osteotomy lines in various orthognathic procedures especially in sagittal split ramus osteotomy to preserve the inferior alveolar nerve. ${ }^{[9,10]}$ A thorough knowledge on the shape and morphometry of the lingula is of great importance for success and safety of the mandibular surgeries and also for inducing inferior alveolar nerve block in various dental treatments involving mandibular teeth. ${ }^{[1]}$ Although a considerable amount of studies have been conducted on lingula anatomy, studies on different populations are still necessary due to the variation of morphological and morphometric properties of lingula among different ethnic groups.

Morphological types of the lingula was first described by Tuli et al. as triangular, nodular, truncated and assimilated. ${ }^{[6]}$ According to their classification, triangular type had a wide base and a narrow rounded or pointed apex, while nodular type was of nodular shape and of variable size. Truncated type had a quadrangular top and assimilated type was completely incorporated into the ramus.

To date, several studies have been performed reporting various distribution and frequency of shapes of lingula across different population and ethnic groups. In a study on 165 dry adult mandibles of Indian origin, Tuli et al., ${ }^{[6]}$ reported that the most common type was triangular (68.5\%), followed by truncated (15.8\%) and nodular
(10.9\%) types and the least was assimilated (4.8\%). Similarly, Gupta and Pandey ${ }^{[12]}$ reported that the incidence of triangular lingula was $50 \%$ and truncated type was $33.82 \%$, while nodular type lingula was $11.76 \%$ and assimilated type was $2.9 \%$ in an Indian population. In another study on Indian population, it was reported that $47.67 \%$ of lingula had triangular shape, $27.97 \%$ were nodular, $13.69 \%$ were assimilated and $10.71 \%$ were truncated. ${ }^{[13]}$ In a study on a Brazilian population, Lopes et al. ${ }^{[14]}$ found that the triangular shape was the most common and assimilated type the least common variety of shape of the lingula. Another study by Kositbowornchai et al. ${ }^{[5]}$ examined 72 dry adult mandibles of Thai origin and found that the truncated shape was observed as the most common shape $(47.2 \%)$, followed by the nodular (22.9\%), triangu$\operatorname{lar}(16.7 \%)$ and assimilated shapes (13.2\%).

Regarding Turkish population, we were able to find two studies evaluating morphology of lingula using CBCT images. One of these studies included 63 patients and the authors reported that the most frequently encountered shape was the nodular type $(32.5 \%)$ and the second was the assimilated (26.2\%), followed by triangular (22.2\%) and truncated (19\%) types. ${ }^{[8]}$ They also reported that bilateral shape $(76 \%)$ was found more often than the unilateral shape (24\%). ${ }^{[8]}$ The other study by Sekerci and Sisman, ${ }^{[7]}$ it was reported that the most common shape was the nodular type $(51.2 \%)$ and the least common was the assimilated type $(2.7 \%)$ while truncated and triangular varieties were present in $32 \%$ and $14.1 \%$ of the mandibles, respectively. ${ }^{[7]}$ In accordance with Senel et al., ${ }^{[8]}$ they found that the bilateral shape $(79.4 \%)$ was more often than the unilateral one $(20.6 \%)$. In contrast to Senel et al. $^{[8]}$ and Sekerci and Sisman, ${ }^{[7]}$ the current study revealed that the most common type was triangular type (42\%), followed by nodular (30\%) and trunculated (28\%), while assimilated type was not observed in the mandibles examined.

Morphometric characteristics of lingula have been studied by many researchers by measuring the height and distance of lingula from various mandibular landmarks.

Table 3

Comparison of height of lingula and distance of lingula from anterior and posterior border of the ramus between right and left sides.

\begin{tabular}{lccccc} 
Groups & Mean \pm SD $(\mathbf{m m})$ & SE mean & $\mathbf{t}$ & df & Sig. (2-tailed) \\
\hline A-right \& A-left & $-.2706 \pm 1.65271$ & .23373 & -1.158 & 49 & .253 \\
P-right \& P-left & $.2924 \pm 1.49032$ & .21076 & 1.387 & 49 & .172 \\
H-right \& H-left & $.23512 \pm 1.47893$ & .22745 & 1.219 & 49 & .311 \\
\hline
\end{tabular}


Jansisyanont et al. ${ }^{[15]}$ examined 92 dried Thai mandibles and reported mean the height of lingula as $8.2 \pm 2.3 \mathrm{~mm}$. Another study by Woo et al. ${ }^{[16]}$ on Korean population, the height of the lingula was found to be $10.51 \pm 3.84 \mathrm{~mm}$. Furthermore, in one other study on 80 dried adult human mandibles of Indian population, Nicholson et al. reported the height of lingula on right side, $8.6 \pm 4.7 \mathrm{~mm}$ and left side, $9.1 \pm 5.7 \mathrm{~mm} .{ }^{[17]}$ In a CBCT study by Sekerci and Sisman on a Turkish population, height of the lingula was measured as $8.03 \pm 1.73 \mathrm{~mm}$ on the right side and $7.82 \pm 1.79$ $\mathrm{mm}$ on the left side. ${ }^{[7]}$ The height of the lingula in the present study was consistent with previous findings, which was $11.75 \pm 1.86 \mathrm{~mm}$ on the right side and $11.99 \pm 1.96 \mathrm{~mm}$ on the left side.

In a study by Samanta et al., ${ }^{[3]}$ the mean distance of lingula from the anterior border of ramus of mandible was measured as $20 \pm 2.4 \mathrm{~mm}$ on Indian population. Likewise, Jansisyanont et al. ${ }^{[15]}$ reported the anterior distance of lingula as $20.6 \pm 3.5 \mathrm{~mm}$ in a Thai population. In another study on Korean population, Woo et al. ${ }^{[16]}$ found the mean anterior distance of lingula as $18.6 \pm 2.5 \mathrm{~mm}$, which was similar to Sekerci and Sisman's ${ }^{[7]}$ findings indicating a mean distance of $16.77 \pm 2.74 \mathrm{~mm}$ in a Turkish population. In the current study, the mean distance from lingula to the anterior border of ramus of mandible was measured as $16.71 \pm 1.88 \mathrm{~mm}$ on the right side and $16.99 \pm 1.94 \mathrm{~mm}$ on the left side.

When it comes to posterior localization, Woo et al. ${ }^{[16]}$ reported the mean distance of lingula from the posterior border of ramus of mandible as $16.1 \pm 3.5 \mathrm{~mm}$ on 20 dry mandibles from a Korean population. In a study on a Thai population, Kositbowornchai et al. ${ }^{[5]}$ found the mean posterior distance of lingula as $15.4 \pm 1.9 \mathrm{~mm}$ on 72 dry mandibles. In another study on Thai population, Jausisyanont et al. ${ }^{[15]}$ examined 92 dry mandibles and reported that the posterior distance of lingula as $18 \pm 2.6$ $\mathrm{mm}$. On the Turkish population, Sekerci and Sisman ${ }^{[7]}$ found a distance of $13.02 \pm 2.31 \mathrm{~mm}$ from the posterior border of the ramus of mandible to the lingula. The distance of lingula from posterior border of ramus of mandible in the present study was consistent with previous findings, which was found to be $14.85 \pm 1.25 \mathrm{~mm}$ on the right side and $14.55 \pm 1.43 \mathrm{~mm}$ on the left side.

\section{Conclusion}

The present study contributes to current knowledge on morphologic and morphometric characteristics of the mandibular lingula in a Turkish population. The most common shape encountered in this study was triangular lingula. The mean height of the lingula was $11.9 \mathrm{~mm}$.
The lingula was located at a mean of $16.9 \mathrm{~mm}$ from the anterior border of the ramus of the mandible, and 14.7 $\mathrm{mm}$ from the posterior border of the ramus of thebmandible. The findings of present study may be useful for various oral and maxillofacial surgical procedures and help surgeons in avoiding inferior alveolar nerve injury during mandibular osteotomies.

\section{Author Contributions}

ÖÖ, EÇ, MS and AS: project planning. HS, BB, SÖ, MSD and MBG: data collection. ÖÖ, HS, BB and AS: data analysis. ÖÖ, EÇ, MS and AS: interpretation of the results. ÖÖ, HS, BB, SÖ, MSD and MBG: writing manuscript. EÇ, MS and AS: final check of the manuscript.

\section{References}

1. Asdullah M, Ansari AA, Khan MH, Salati NA, Khawja KJ, Sachdev AS. Morphological variations of lingula and prevalence of accessory mandibular foramina in mandibles: a study. Natl J Maxillofac Surg 2018;9:129-33.

2. Antony P, Sebastian A, Varghese KG, Sobhana C, Mohan S, Soumithran C, Domnic S, Jayakumar N. Neurosensory evaluation of inferior alveolar nerve after bilateral sagittal split ramus osteotomy of mandible. J Oral Biol Craniofac Res 2017;7:81-8.

3. Samanta PP, Kharb P. Morphological analysis of the lingula in dry adult human mandibles of north Indian population. Journal of Cranio-Maxillary Diseases 2012;1:7-11.

4. Kim HJ, Lee HY, Chung IH, Cha IH, Yi CK. Mandibular anatomy related to sagittal split ramus osteotomy in Koreans. Yonsei Med J 1997;38:19-25.

5. Kositbowornchai S, Siritapetawee M, Damrongrungruang T, Khongkankong $\mathrm{W}$, Chatrchaiwiwatana S, Khamanarong $\mathrm{K}$, Chanthaooplee T. Shape of the lingula and its localization by panoramic radiograph versus dry mandibular measurement. Surg Radiol Anat 2007;29:689-94.

6. Tuli A, Choudhry R, Choudhry S, Raheja S, Agarwal S. Variation in shape of the lingula in the adult human mandible. J Anat 2000;197: 313-7.

7. Sekerci AE, Sisman Y. Cone-beam computed tomography analysis of the shape, height, and location of the mandibular lingula. Surg Radiol Anat 2014;36:155-62.

8. Senel B, Ozkan A, Altug HA. Morphological evaluation of the mandibular lingula using cone-beam computed tomography. Folia Morphol (Warsz) 2015;74:497-502.

9. Nishioka GJ, Aragon SB. Modified sagittal split technique for patients with a high lingula. J Oral Maxillofac Surg 1989;47:4267.

10. Smith BR, Rajchel JL, Waite DE, Read L. Ramus of mandible anatomy as it relates to the medial osteotomy of the sagittal split ramus osteotomy. J Oral Maxillofac Surg 1991;49:112-6.

11. Lima F, Neto OO, Barbosa F, Sousa-Rodrigues C. Location, shape and anatomic relations of the mandibular foramen and the mandibular lingula: a contribution to surgical procedures in the ramus of the mandible. Oral Maxillofac Surg 2016;20:177-82. 
12. Gupta S, Pandey K. Morphological analysis of the lingula in dry mandibles of individuals in North India. IOSR Journal of Dental Medical Sciences 2014;13:4-6.

13. Nirmale V, Mane U, Sukre S, Diwan C. Morphological features of human mandible. International Journal of Recent Trends in Sciences Technology 2012;2:38-43.

14. Lopes P, Pereira G, Santos A. Morphological analysis of the lingula in dry mandibles of individuals in Southern Brazil. Journal of Morphological Sciences 2010;27:136-8.

ORCID ID:

Ö. Özalp 0000-0003-4350-1975; H. Salım 0000-0002-7231-9526; B. Bilgin 0000-0003-1637-8350; S. Öztürk 0000-0003-1002-0059; M. Sarıkaya Doğan 0000-0002-1781-3505. M. B. Göztepe 0000-0002-1193-3696; E. Çalgüner 0000-0001-8248-5096; M. Sindel 0000-0002-6594-1325; A. Sindel 0000-0001-8760-5958 deomed.
15. Jansisyanont $P$, Apinhasmit $W$, Chompoopong S. Shape, height, and location of the lingula for sagittal ramus osteotomy in Thais. Clin Anat 2009;22:787-93.

16. Woo SS, Cho JY, Park WH, Yoo IH, Lee YS, Shim KS. A study of mandibular anatomy for orthognathic surgery in Koreans. Journal of Korean Association of Oral and Maxillofacial Surgery 2002;28:12631.

17. Nicholson ML. A study of the position of the mandibular foramen in the adult human mandible. Anat Rec (Hoboken) 1985;212:110-2.

Correspondence to: Öznur Özalp, DDS

Department of Oral and Maxillofacial Surgery,

School of Dentistry, Akdeniz University, Antalya, Turkey

Phone: +90 2422274400 - 5887

e-mail: oznur_ozalp_@hotmail.com

Conflict of interest statement: No conflicts declared.

This is an open access article distributed under the terms of the Creative Commons Attribution-NonCommercial-NoDerivs 3.0 Unported (CC BY-NCND3.0) Licence (http://creativecommons.org/licenses/by-nc-nd/3.0/) which permits unrestricted noncommercial use, distribution, and reproduction in any medium, provided the original work is properly cited. Please cite this article as: Özalp Ö, Salım H, Bilgin B, Öztürk S, Sarıkaya Doğan M, Göztepe MB, Çalgüner E, Sindel M, Sindel A. Morphologic and morphometric analysis of mandibular lingula. Anatomy 2020;14(1):16-21. 